\title{
Deep Brain Stimulation and Behavioural Changes: Is Comedication the Most Important Factor?
}

\author{
Dorothée Lulé ${ }^{a-c}$ Johanna Heimrath ${ }^{a, b}$ Elmar H. Pinkhardt ${ }^{a}$ \\ Albert C. Ludolph ${ }^{a}$ Ingo Uttner ${ }^{a}$ Jan Kassubek ${ }^{a, b}$ \\ a Department of Neurology and bection of Neurophysiology, Department of Neurology, University of Ulm, \\ Ulm, and ${ }^{\mathrm{C}}$ Institute of Medical Psychology and Behavioural Neurobiology, Eberhard Karl University of Tübingen, \\ Tübingen, Germany
}

\section{Key Words}

Parkinson's disease $\cdot$ Deep brain stimulation - Dopamine dysregulation syndrome $\cdot$ Executive function $\cdot$ Gambling

\begin{abstract}
Background: Adverse effects of dopaminergic medication (DA; levodopa and dopamine agonists) on impulsive behaviour and decision-making in patients with Parkinson's disease (PD) have been repeatedly reported. Deep brain stimulation (DBS) is increasingly used for the treatment of parkinsonian motor symptoms, but the excellent efficacy of DBS contrasts with a growing number of reports that the treatment may result in behavioural complications. Aims: We investigated impulsive behaviour under different therapeutic treatments. Methods: Fifteen patients with PD with DBS (PD-DBS) were assessed with electrical stimulation switched on and off, respectively. Data were compared with those of 15 patients with PD without DBS implantation under DA medication (PD-DA), matched for age and disease duration. Impulsive behaviour (gambling performance) was measured together with neuropsychological assessments regarding depression, current mood and cognitive performance. Results: PD-DA patients performed worse in the gambling task than DBS patients with electrical stimulation turned off. A
\end{abstract}

significant interaction of performance and medication was observed. When DBS was turned on, the differences in performance were less pronounced. Conclusion: For gambling performance, the medication dose mainly explains differences in impulsive behaviour. Although DBS had a minor negative effect on impulsive behaviour, the positive effect of a reduced DA dosis after DBS might reduce impulse control abnormalities.

Copyright $\odot 2011$ S. Karger AG, Basel

\section{Introduction}

Deep brain stimulation (DBS) of the subthalamic nucleus (STN) is increasingly applied in Parkinson's disease (PD) [1]. DBS enables the reduction of the daily dosage of levodopa by $40-80 \%$. It improves not only levodopasensitive motor functions by $60-80 \%$, but also relieves adverse effects of pharmacological treatment [2]. The therapy with high-dose dopaminergic medication (DA; levodopa or dopamine agonists) is associated with sub-

D. Lulé and J. Heimrath contributed equally to the manuscript. I. Uttner and J. Kassubek shared senior authorship.

\section{KARGER \\ Fax +4161306 1234 \\ E-Mail karger@karger.ch}

www.karger.com
(C) 2011 S. Karger AG, Basel

$1660-2854 / 12 / 0091-0018 \$ 38.00 / 0$

Accessible online at:

www.karger.com/ndd
Dr. rer. nat. Dorothée Lulé, $\mathrm{PhD}$

Department of Neurology/Section of Neurophysiology

University of Ulm, Albert-Einstein-Allee 47

DE-89081 Ulm (Germany)

Tel. +49 7315006 3076, E-Mail dorothee.lule@uni-ulm.de 
stantial alterations in behaviour in $14-17 \%$ of cases. This may result in a sensitization towards impulse control disorder (ICD), a group of psychiatric disorders whose essential feature is the failure to resist an act or behaviour with harmful consequences for oneself or others [3]. There is strong evidence of an association between DA medication in PD patients and a range of ICDs [4]. In a cross-sectional study on over 3,000 PD patients, ICDs were increased with a prevalence of $14 \%$ [5]. Pathological gambling (PG) as one presentation of ICD is reported in about $1.7-6 \%$ of DA-medicated patients [6-13]. While the first reports concerning PG were on PD patients under high doses of DA medication [10-12], moderate doses [14] or low doses of DA [15] were also reported to cause sensitization towards ICD. After discontinuation of the treatment, the predisposition towards PG usually subsides [12]. Drug-naïve patients have no increased prevalence for ICD [16].

The favourable effect of STN-DBS on motor and cognitive functions contrasts with a growing number of reports that the treatment may result in several cognitive and behavioural alterations, such as impairment of verbal fluency, working memory and processing speed [17], depression [2], mania [18], apathy [19] and a loss of impulse control [20]. PG has evolved under DBS in several cases $[5-8,21]$.

The possible effects of DBS on non-motor behaviour and especially the interaction of STN-DBS and DA medication need to be examined. In this study, the effect of DBS and different doses of DA medication on changes in gambling performance towards riskiness and impulsivity were examined. Patients were either tested on high (PD patients without DBS) or low doses of DA medication (PD patients with DBS), and with electrical stimulation either turned on or turned off in PD patients with DBS. The study aims to contribute to the understanding of behavioural dyscontrol in PD patients under different therapeutic options.

\section{Methods}

\section{Participants}

All data are given as means \pm standard deviation (SD). Fifteen PD patients with DBS (PD-DBS; 4 women, 11 men; age 63.9 \pm 6.6 years) participated in the study. The patients were sequentially chosen after DBS implantation in our clinic ( $>1$ month after surgery). The electrodes had been implanted stereotactically in the STN; all PD-DBS patients had received quadripolar electrodes (Medtronic Inc., Minneapolis, Minn., USA). The mean time since implantation of the DBS device was $18.7 \pm 21.1$ months (range 1-61). Post hoc analysis of CT scans in 10 patients
Table 1. Characteristics of patients with DBS (PD-DBS) and without DBS (PD-DA)

\begin{tabular}{|c|c|c|c|c|}
\hline & \multicolumn{2}{|l|}{ PD-DBS } & \multicolumn{2}{|l|}{ PD-DA } \\
\hline & $\begin{array}{l}\text { mean } \\
\pm \mathrm{SD}\end{array}$ & range & $\begin{array}{l}\text { mean } \\
\pm S D\end{array}$ & range \\
\hline Age, years & $63.9 \pm 6.6$ & $51-74$ & $63.8 \pm 12.5$ & $43-80$ \\
\hline UPDRS (DBS: on) & $32 \pm 18$ & $5-62$ & $21 \pm 12$ & $2-56$ \\
\hline $\begin{array}{l}\text { Time since diagnosis, } \\
\text { months }\end{array}$ & $127 \pm 48$ & $48-228$ & $125 \pm 68.5$ & $24-240$ \\
\hline $\begin{array}{l}\text { Time since implan- } \\
\text { tation, months }\end{array}$ & $18.7 \pm 21.1$ & $1-61$ & - & - \\
\hline
\end{tabular}

revealed correct lateral placement of electrodes in basal ganglia in $90 \%$ standard range according to Guridi et al. [22]. The mean clinical disease severity of the PD-DBS patients was $32 \pm 18$ (range 5-62), as measured by the Unified Parkinson Disease Rating Scale (UPDRS) motor scale in the on state. The mean duration of the disease for PD-DBS patients was $127 \pm 48$ months (range 48-228), as determined by the onset of motor symptoms (table 1).

One of 15 PD patients with DBS received a monotherapy with levodopa in a daily dosage of $450 \mathrm{mg}$. Five of $15 \mathrm{PD}$ patients with DBS were medicated with dopamine agonists in a levodopaequivalent dosage of $193 \pm 83 \mathrm{mg}$ (range 54-270). Six of the 15 PD patients with DBS received a combination of levodopa + dopamine agonists with a levodopa dosage of $375 \pm 94 \mathrm{mg}$ (range $250-500)$ and a levodopa-equivalent agonist dosage of $408 \pm 291$ mg (range 132-770), calculated according to Tomlinson et al. [23] (table 2). Three patients received no DA medication.

Additionally, 15 patients without DBS who were under DA medication only were included. One patient with a medication dose $>2$ SD from average was excluded from statistics. Two of 14 PD-DA patients without DBS were medicated with dopamine agonists only in a levodopa-equivalent daily dosage of $315 \pm 191 \mathrm{mg}$ (range 180-450). Twelve of 14 PD-DA patients without DBS received a combination of levodopa + dopamine agonists with a levodopa dosage of $443 \pm 339 \mathrm{mg}$ (range 75-1,100) and a levodopa-equivalent agonist dosage of $423 \pm 240 \mathrm{mg}$ (range 53-775; table 2).

All of the participants were free of any central nervous system medication besides the DA medication. The patients had been clinically and neuropsychologically assessed. None of the patients presented evidence for PG.

The study had been approved by the ethics committee of the University of Ulm and was performed in accordance with the ethical standards of the Declaration of Helsinki. All subjects gave their informed consent prior to their inclusion in the study.

\section{Design}

PD-DBS patients were measured twice: once with DBS stimulation turned on (PD-DBS on state) and once with the DBS stimulation turned off for at least $30 \mathrm{~min}$ (PD-DBS off state). According to Lopiano et al. [24], the main effect of open-circuit DBS on motor performance is expected $30-45 \mathrm{~min}$ after switch-off. A longer 
Table 2. Medication (mg) of patients with DBS (PD-DBS) and without DBS (PD-DA)

\begin{tabular}{|c|c|c|c|c|c|c|c|c|}
\hline & \multicolumn{4}{|c|}{ PD-DBS } & \multicolumn{4}{|c|}{ PD-DA } \\
\hline & $\mathrm{n}$ & mean & $\mathrm{SD}$ & range & $\mathrm{n}$ & mean & SD & range \\
\hline Levodopa & 7 & 386 & 90 & $250-500$ & 12 & 443 & 339 & $75-1,100$ \\
\hline Pramipexole (salt) & 2 & 2 & 2 & $0.54-3.15$ & 3 & 1 & 1 & $0.53-1.75$ \\
\hline Amantadine & 2 & 200 & 0 & 200 & 0 & NA & NA & NA \\
\hline Entacapone & 4 & 800 & 163 & $800-1,000$ & 3 & 492 & 166 & $300-600$ \\
\hline Ropinirole & 3 & 11 & 1 & $10-12$ & 7 & 17 & 8 & $8-28$ \\
\hline Cabergoline & 2 & 7 & 4 & $4-10$ & 0 & NA & NA & NA \\
\hline Pergolide & 1 & 5 & NA & NA & 2 & 8 & 1 & $4.5-12$ \\
\hline Apomorphine & 1 & 8 & NA & NA & 3 & 42 & 17 & $26-60$ \\
\hline Rotigotine & 0 & NA & NA & NA & 2 & 5 & 1 & $4-6$ \\
\hline None & 3 & NA & NA & NA & 0 & NA & NA & NA \\
\hline
\end{tabular}

NA $=$ Not applicable

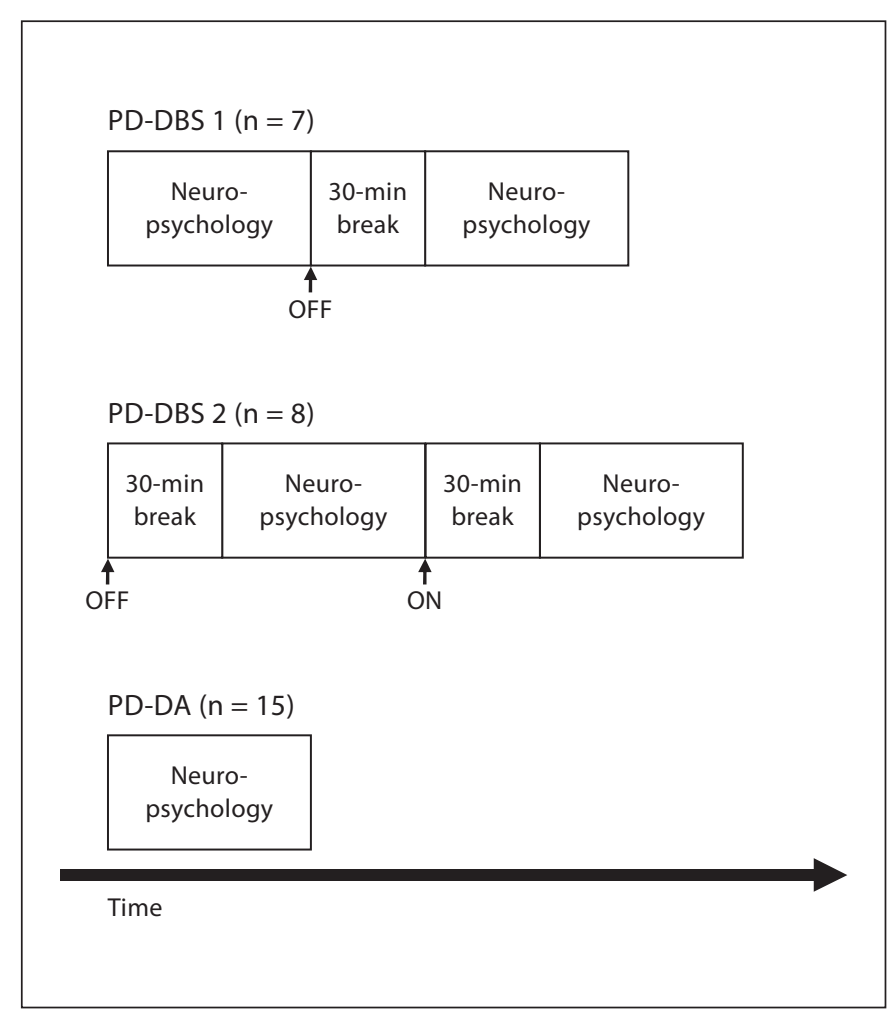

Fig. 1. Design of the study. PD patients with implanted STN stimulation were measured twice, either with the DBS first turned on and then turned off (PD-DBS 1: 7 subjects) or first with the stimulation turned off before turning it on (PD-DBS 2: 8 subjects). time window of open-circuit DBS before starting neuropsychological assessment was considered to be intolerable for the patients.

There was a random order for the PD-DBS on state and off state measurements (fig. 1). PD-DA patients were measured only once.

\section{Neuropsychological Assessment}

General psychometric investigation included the Parkinson Neuropsychometric Dementia Assessment [25], a German adaptation of the Stroop Test [26], a vocabulary test (Wortschatztest) [27] and the Geriatric Depression Scale (GDS) [28]. Those tests were only measured once in the on state. The current mood of the patient concerning depressive mood, fear and irritability was evaluated by a 5 -point Likert scale ( 1 as the lowest expression of mood and 5 as the strongest current mood possible) in the off and the on states.

Decision-making was evaluated with a PC-based version of the Iowa gambling task [29]. In this task, 4 different options of card decks are available, and participants have to choose from which deck they want to pick a card. Decks A and B are more disadvantageous decks (high amounts of virtual 'money' to win but even higher amounts to lose) and decks $\mathrm{C}$ and $\mathrm{D}$ are more advantageous (low amounts of 'money' to win but a positive balance in the end). Participants had no prior information about the cards. Feedback regarding either winning or losing of 'money' after each of 100 trials was the only information given to the participants. The goal is to 'earn' as much money as possible within 100 turns. In the task, we counted the number of selections from disadvantageous and the number of advantageous selections for each bin, i.e. block of 20 cards. Gambling scores $[(C+D)-(A+B)]$ were then derived for each bin [30] (5 gambling scores in total for each participant over the course of the experiment). Net scores below zero indicate that the subjects were selecting disadvantageously, whereas net scores above zero indicate that subjects were selecting advantageously.

\section{Statistics}

Data were subjected to repeated-measure ANOVAs. Betweensubject factor was group (PD without DBS vs. PD with DBS on 
and vs. PD with DBS off), and within-subject factor was stimulation (PD-DBS on state vs. PD-DBS off state). For gambling performance, bins as within-subject factor were chosen. To estimate the effect of depression and medical treatment on gambling performance, the model was corrected for depression (GDS) and DA medication doses.

Univariate ANOVA was applied to compare general psychometric investigation in PD-DA patients and PD-DBS patients. A repeated-measure ANOVA was performed to compare mood measurements in the on and off states. Correlation analysis was used to test for directedness of effects. A threshold with $\mathrm{p}<0.05$ was chosen for all statistical inferences. Statistical analysis was performed using the Statistical Package for the Social Sciences (SPSS, version 16, Stanford, Calif., USA).

\section{Results}

Significant improvement in motor function associated with stimulation on compared to stimulation off was reflected in a higher UPDRS motor score in the off state (on UPDRS $=32 \pm 18$, off UPDRS $=42 \pm 15 ; \mathrm{p}<0.001$ )

\section{Neuropsychological Assessments}

The scores for neuropsychological assessments are given in table 3. PD-DBS patients in the on state presented higher irritability $(2.4 \pm 1.2)$ compared to $\mathrm{PD}$ DA patients without DBS $(1.6 \pm 0.7$; ANOVA $F=4.2$, $\mathrm{p}=0.05)$. There was no significant difference in any other of the neuropsychological tests for PD-DBS patients compared to PD-DA patients. There was no significant difference in the mood measurements for PD-DBS patients in the on compared to the off state (data not shown).

\section{Gambling Performance}

For PD-DA and PD-DBS patients in the on state, there was no significant main effect; there was a trend for the interaction of the gambling performance with group $($ ANOVA $\mathrm{F}=2.2, \mathrm{p}=0.07)$ and medication (ANOVA $\mathrm{F}=$ $2.3, \mathrm{p}=0.07)$ which did not reach the threshold for significance (table 4).

There was a trend for the correlation analysis of medication and gambling performance: the higher the medication, the lower the Iowa gambling task score and the more disadvantageous the choice of cards (Pearson correlation $r=-0.3$ with $p=0.1$. No effect of depression rate (GDS score) was observed.

For PD-DA patients compared to PD-DBS patients in the off state, there was a significant main effect for bins (ANOVA $F=3.9, p<0.01$ ) suggesting that gambling performance changed throughout the experiment: pa-
Table 3. Synopsis of neuropsychological assessments (means \pm $\mathrm{SD}$ ) in PD patients with DBS and in patients with DA medication only

\begin{tabular}{lcc}
\hline & PD-DBS & PD-DA \\
\hline WST & $99.4 \pm 8.9$ & $93.5 \pm 11.0$ \\
PANDA & $16.5 \pm 4.8$ & $18.4 \pm 6.4$ \\
GDS & $3.3 \pm 2.9$ & $4.2 \pm 3.1$ \\
Stroop FWT & $35.8 \pm 22.0$ & $30.2 \pm 15.3$ \\
Mood rating & & \\
$\quad$ Depressive & $2.2 \pm 1.4$ & $2.1 \pm 1.2$ \\
$\quad$ Anxious & $1.4 \pm 0.9$ & $1.3 \pm 0.6$ \\
$\quad$ Irritable* & $2.4 \pm 1.2$ & $1.6 \pm 0.7$ \\
\hline \multicolumn{2}{l}{ WST $=$ Wortschatztest (vocabulary } & recognition $\quad$ test); \\
PANDA = Parkinson Neuropsychometric Dementia Assessment; \\
FWT = Farbwort-Test (colour word test; interference score). For \\
PD-DBS patients, all values are given for the on state. ${ }^{*}$ p $=0.05:$ \\
significant difference between groups (ANOVA). \\
\hline
\end{tabular}

Table 4. Gambling performance (means $\pm \mathrm{SD}$ ) in PD patients with DBS either in the on or off state and in patients with DA medication only

\begin{tabular}{lrcl}
\hline IGT & PD-DBS on & PD-DBS off & \multicolumn{1}{l}{ PD-DA } \\
\hline Score & $4.6 \pm 21.0$ & $4.4 \pm 28.5^{*}$ & $-3.5 \pm 17.9$ \\
A + B & $47.7 \pm 10.5$ & $47.8 \pm 14.3$ & $51.7 \pm 9.0$ \\
C + D & $52.3 \pm 10.5$ & $52.2 \pm 14.3$ & $48.3 \pm 9.0$ \\
\hline
\end{tabular}

The higher the score, the less disadvantageous cards were chosen and the lower the risky behaviour. IGT = Iowa gambling task; $\mathrm{A}+\mathrm{B}=$ decks with disadvantageous cards; $\mathrm{C}+\mathrm{D}=$ decks with advantageous cards. ${ }^{*} \mathrm{p}=0.02$ : significant interaction (ANOVA) for choice of cards and group (PD-DBS off and PD-DA).

tients 'learned' and chose more advantageous cards and had a higher gambling score in the course of 100 trials. However, there was a significant interaction of bins and group (ANOVA $F=2.7, p=0.03$ ), suggesting that the gambling performance of $\mathrm{PD}-\mathrm{DA}$ patients and $\mathrm{PD}-\mathrm{DBS}$ patients in the off state was significantly different: PDDA patients did not 'learn' as well, kept choosing less advantageous cards and thus had a lower gambling score in the course of 100 trials compared to PD-DBS patients (table 4). There was a significant interaction of gambling performance with medication: the lower the medication, the more advantageous cards chosen and the high- 
er the gambling score (ANOVA $\mathrm{F}=3.2, \mathrm{p}=0.02$ ). No effect of depression rate (GDS score) on gambling performance was observed.

For PD-DBS patients in the on compared to the off state, there was no significant main effect. There was no effect for gambling performance, group and medication (table 4). Correlation analysis revealed that the more fear the patients felt, the more there was a bias in the choice of advantageous cards (correlation between fear and choice $\mathrm{A}$ and $\mathrm{B}, \mathrm{r}=-0.4, \mathrm{p}=0.04$, and choice $\mathrm{C}$ and $\mathrm{D}, \mathrm{r}=0.4$, $\mathrm{p}=0.04$, respectively).

\section{Discussion}

The purpose of the study was to test which effect DBS or rather different doses of DA medication had on risky behaviour and impulsivity in PD. To evaluate the effect of medical treatment, patients were either tested on high (PD patients without DBS) or low doses of DA medication (PD patients with DBS). The effect of electrical stimulation was tested by comparing PD patients with DBS either turned on or off.

PD-DA patients with high DA medication chose more often disadvantageous decks of cards than PD-DBS patients in the off state. In the course of the experiment, PD-DA patients did not change the strategy according to the negative experiences of high losses of the disadvantageous card decks. Medication was a factor for risky behaviour. Patients with low DA medication (patients with implanted DBS when DBS is turned off) and healthy controls in other studies [30] gradually shifted their preference towards the advantageous decks (C and D) and away from the 'bad' decks, as reflected by the shift in the net scores towards positivity. PD patients with high DA medication performed like patients with ventromedial lesions who failed to present this shift in behaviour [30]. A reduction of DA medication after DBS implantation might account for this difference of reduced risky behaviour throughout the experiment and therefore improved gambling performance. This is supported by the fact that differences in gambling performance between PD patients with high (PD-DA patients) and low DA medication (PD-DBS patients) significantly interacted with dose of medication in the present study. The trend in correlation analysis revealed that the higher the DA medication, the more disadvantageous cards were chosen. The trend for an interaction of risky behaviour in gambling performance and medication for PD-DA patients and PD-DBS patients in the on state further supports this no- tion of a general medication effect in patients under DA medication in terms of a sensitization towards a more risky behaviour and a higher impulsivity in decisionmaking $[9,31,32]$.

The observation that differences between PD-DBS patients in the on state and PD-DA patients in gambling performance were less pronounced than differences between PD-DBS patients in the off state and PD-DA patients supports the assumption that DBS may additionally interact with frontal circuits involved in decision-making. STN-DBS may have an effect on the frontolimbic basal ganglia and ventromedial prefrontal cortex loops via dopaminergic projection neurons [33]. Findings by Frank [31] support this notion of an interference of DBS with the normal ability to slow down when faced with decision conflict. Accordingly, impulsivity is increased under DBS, and the number of errors in a task may increase. The increased impulsivity under DBS due to overstimulation of the frontolimbic-basal ganglia loop [31] may explain the cases of PG reported in DBS patients $[21,34]$ which might counteract the positive effects of DBS on impulsive behaviour named above by reducing the need for high doses of DA medication. The trend for an interaction of risky behaviour in gambling performance and group for PD-DBS patients in the on state and PD-DA patients supports the notion of an interaction of DBS with gambling performance. Due to the low number of participants, this might not have reached statistical significance. Further studies are needed.

The open question whether DBS has a positive or negative effect on gambling performance might be explained by different time scales investigated in studies. On the short run (i.e. after $30 \mathrm{~min}$ like in this study), DBS might have a negative effect on decision-making by increasing the impulsivity of PD patients. The fact that differences in risky behaviour during gambling performance between PD patients with DBS turned on versus DBS turned off was not significant in the present study suggests that this effect is rather small. On the long run (i.e. months after implantation), secondary positive effects of DBS on motor and socio-economic factors and the positive effect of DA medication reduction after DBS mentioned above might contribute to the easing-off of impulsive behaviour in PD patients [2]. The short period of non-stimulation in the DBS group in the off state is a shortcoming of the study which limits any general conclusions with this regard. However, a longer period increased unpleasant motor symptoms and was therefore intolerable for the patients. Another limitation of our 
study was the fact that there was a wide range of levodopa-equivalent doses in our patients and a difference of DA medication between PD-DBS and PD-DA patients. Any differences between groups might be confounded by this difference in medication. Furthermore, due to small sample sizes (e.g. only 1 PD-DBS patient with levodopa only), comparison between different medication groups was excluded. Despite this difference in medication, there was a positive effect between impulsive behaviour and medication. The comparison of data in on and off states remains unaffected by this limitation. Small sample size is a caveat and a limitation of the interpretability of the results so that further investigation of medication effects on ICD is mandatory.

\section{Conclusion}

The study brought evidence that effects of DBS on risky decision-making behaviour may be confounded by pharmacological (dopaminergic) effects. The data support the effect of medication dose on decision-making in PD patients. These data contribute to the understanding of behavioural dyscontrol previously reported in patients with PD under different treatments [35-37].

\section{Disclosure Statement}

None of the authors reports any competing interests.

\section{References}

1 Deuschl G: Neurostimulation for Parkinson disease. JAMA 2009;301:104-105.

2 Houeto JL, Mallet L, Mesnage V, Tezenas du Montcel S, Béhar C, Gargiulo M, Torny F, Pelissolo A, Welter ML, Agid Y: Subthalamic stimulation in Parkinson disease: behavior and social adaptation. Arch Neurol 2006;63: 1090-1095.

3 Saß H, Wittchen H-U, Zaudig M: Diagnostisches und Statistisches Manual Psychischer Störungen (DSM-IV-TR): Textrevision. Göttingen, Hogrefe, 2003.

-4 Weintraub D, Hoops S, Shea JA, Lyons KE, Pahwa R, Driver-Dunckley ED, Adler CH, Potenza MN, Miyasaki J, Siderowf AD, Duda JE, Hurtig HI, Colcher A, Horn SS, Stern $\mathrm{MB}$, Voon V: Validation of the questionnaire for impulsive-compulsive disorders in $\mathrm{Par}$ kinson's disease. Mov Disord 2009;24:14611467.

$\checkmark 5$ Weintraub D, Siderowf AD, Potenza MN, Goveas J, Morales KH, Duda JE, Moberg PJ, Stern MB: Association of dopamine agonist use with impulse control disorders in Parkinson disease. Arch Neurol 2006;63:969973.

6 Voon V, Hassan K, Zurowski M, Duff-Canning S, de Souza M, Fox S, Lang AE, Miyasaki J: Prospective prevalence of pathologic gambling and medication association in Parkinson disease. Neurology 2006;66:17501752.

7 Voon V, Hassan K, Zurowski M, de Souza M, Thomsen T, Fox S, Lang AE, Miyasaki J: Prevalence of repetitive and reward-seeking behaviors in Parkinson disease. Neurology 2006;67:1254-1257.

DBS, Medication and Behavioural Changes
8 Weintraub D, Koester J, Potenza MN, Siderowf AD, Stacy M, Voon V, Whetteckey J, Wunderlich GR, Lang AE: Impulse control disorders in Parkinson disease: a cross-sectional study of 3,090 patients. Arch Neurol 2010;67:589-595.

-9 Abler B, Hahlbrock R, Unrath A, Grön G, Kassubek J: At-risk for pathological gambling: imaging neural reward processing under chronic dopamine agonists. Brain 2009; 132:2396-2402.

10 Dodd ML, Klos KJ, Bower JH, Geda YE, Josephs KA, Ahlskog E: Pathological gambling caused by drugs used to treat Parkinson disease. Arch Neurol 2005;62:1-5.

11 Gallagher DA, O'Sullivan SS, Evans AH, Lees AJ, Schrag S: Pathological gambling in Parkinson's disease: risk factors and differences from dopamine dysregulation. Analysis of published case series. Mov Disord 2007; 22:1757-1763.

12 Voon V, Thomsen T, Miyasaki JM, et al: Factors associated with dopaminergic drug-related pathological gambling in Parkinson disease. Arch Neurol 2007;64:212-216.

13 Wolters EC, van der Werf YD, van den Heuvel OA: Parkinson's disease-related disorders in the impulsive-compulsive spectrum. J Neurol 2008;255:48-56.

14 Bostwick JM, Hecksel KA, Stevens SR, Bower JH, Ahlskog JE: Frequency of new-onset pathologic compulsive gambling or hypersexuality after drug treatment of idiopathic Parkinson disease. Mayo Clin Proc 2009;84: 310-316.

15 Driver-Dunckley E, Noble BN, Hentz JG, et al: Gambling and increased sexual desire with dopaminergic medications in restless legs syndrome. Clin Neuropharmacol 2007; 30:249-255.
16 Antonini A, Siri C, Santangelo G, Cilia R, Poletti M, Canesi M, Caporali A, Mancini F, Pezzoli G, Ceravolo R, Bonuccelli U, Barone $\mathrm{P}$ : Impulsivity and compulsivity in drug-naivve patients with Parkinson's disease. Mov Disord 2011;26:464-468.

17 Parsons TD, Rogers SA, Braaten AJ, Woods SP, Tröster AI: Cognitive sequelae of subthalamic nucleus deep brain stimulation in Parkinson's disease: a meta-analysis. Lancet Neurol 2006;5:578-588.

18 Daniele A, Albanese A, Contarino MF, Zinzi P, Barbier A, Gasparini F, Romito LM, Bentivoglio AR, Scerrati M: Cognitive and behavioural effects of chronic stimulation of the subthalamic nucleus in patients with Parkinson's disease. J Neurol Neurosurg Psychiatry 2003;74:175-182.

19 Contarino MF, Daniele A, Sibilia AH, Romito LM, Bentivoglio AR, Gainotti G, Albanese A: Cognitive outcome 5 years after bilateral chronic stimulation of subthalamic nucleus in patients with Parkinson's disease. J Neurol Neurosurg Psychiatry 2007;78:248-252.

20 Hälbig TD, Tse W, Frisina PG, Baker BR, Hollander E, Shapiro H, Tagliati M, Koller WC, Olanow CW: Subthalamic deep brain stimulation and impulse control in Parkinson's disease. Eur J Neurol 2009;16:493-497.

-21 Lu C, Bharmal A, Suchowersky O: Gambling and Parkinson disease. Arch Neurol 2006; 63:298.

-22 Guridi J, Rodriguez-Oroz MC, Lozano AM Moro E, Albanese A, Nuttin B, Gybels J, Ramos E, Obeso JA: Targeting the basal ganglia for deep brain stimulation in Parkinson's disease. Neurology 2000;55:21-28. 
-23 Tomlinson CL, Stowe R, Patel S, Rick C, Gray $\mathrm{R}$, Clarke CE: Systematic review of levodopa dose equivalency reporting in Parkinson's disease. Mov Disord 2010;25:2649-2653.

24 Lopiano L, Torre E, Benedetti F, et al: Temporal changes in movement time during the switch of the stimulators in Parkinson's disease patients treated by subthalamic nucleus stimulation. Eur Neurol 2003;50:94-99.

25 Kalbe E, Calabrese P, Kohn N, Hilker R, Riedel O, Wittchen HU, Dodel R, Otto J, Ebersbach G, Kessler J: Screening for cognitive deficits in Parkinson's disease with the Parkinson neuropsychometric dementia assessment (PANDA) instrument. Parkinsonism Relat Disord 2008;14:93-101.

26 Oswald W, Fleischmann U: Nürnberger-Alters-Inventar (NAI), ed 4. Göttingen, Hogrefe, 1999.

27 Schmidt K-H, Metzler P: WST-Wortschatztest. Diagnostica 1994;40:293-297.

-28 Sheikh JI, Yesavage JA: Geriatric Depression Scale (GDS): recent evidence and development of a shorter version. Clin Gerontol 1986;5:165-173.
29 Bechara A, Damásio AR, Damásio H, Anderson SW: Insensitivity to future consequences following damage to human prefrontal cortex. Cognition 1994;50:7-15.

30 Bechara A, Tranel D, Damasio H: Characterization of the decision-making deficit of patients with ventromedial prefrontal cortex lesions. Brain 2000;123:2189-2202.

31 Frank MJ: Hold your horses: a dynamic computational role for the subthalamic nucleus in decision making. Neural Netw 2006;19: 1120-1136.

32 Frank MJ, Samanta J, Moustafa AA, Sherman SJ: Hold your horses: impulsivity, deep brain stimulation, and medication in parkinsonism. Science 2007;318:1309-1312.

33 Alegret M, Junque C, Valldeoriola F, et al: Effects of bilateral subthalamic stimulation on cognitive function in Parkinson disease. Arch Neurol 2001;58:1223-1227.
4 Smeding HM, Goudriaan AE, Foncke EM, Schuurman PR, Speelman JD, Schmand B: Pathological gambling after bilateral subthalamic nucleus stimulation in Parkinson disease. J Neurol Neurosurg Psychiatry 2007;78: 517-519.

35 Saint-Cyr JA, Trepanier LL, Kumar R, Lozano AM, Lang AE: Neuropsychological consequences of chronic bilateral stimulation of the subthalamic nucleus in Parkinson's disease. Brain 2000;123:2091-2108.

36 Schroeder U, Kuehler A, Hennenlotter A, Haslinger B, Tronnier VM, Krause M, Pfister R, Sprengelmeyer R, Lange KW, CeballosBaumann AO: Facial expression recognition and subthalamic nucleus stimulation. J Neurol Neurosurg Psychiatry 2004;75:648-650.

37 Houeto JL, Mesnage V, Mallet L, Pillon B, Gargiulo M, du Moncel ST, Bonnet AM, Pidoux B, Dormont D, Cornu P, Agid Y: Behavioural disorders, Parkinson's disease and subthalamic stimulation. J Neurol Neurosurg Psychiatry 2002;72:701-707. 